SANTOS, P.R. e SOUZA, F.S. O uso da atividade assistida por animais em pacientes com paralisia cerebral na cidade de Manaus-AM. PUBVET, Londrina, V. 5, N. 37, Ed. 184, Art. $1243,2011$.

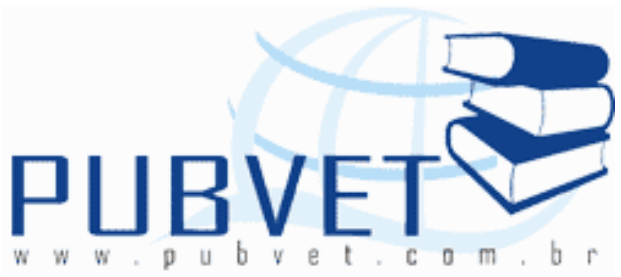

PUBVET, Publicações em Medicina Veterinária e Zootecnia.

\title{
O uso da atividade assistida por animais em pacientes com paralisia cerebral na cidade de Manaus-AM
}

\section{Patrícia Reis dos Santos ${ }^{1}$ e Fábio Silva de Souza ${ }^{2}$}

${ }^{1}$ Médica Veterinária autônoma. E-mail: patie_br@yahoo.com.br

${ }^{2}$ Prof. do curso de Medicina Veterinária da Escola Superior Batista do Amazonas. E-mail: souzamedvet@yahoo.com.br

\section{Resumo}

O presente estudo procurou mostrar a Atividade Assistida por Animais voltada para pacientes com distúrbios neurológicos, focalizado na paralisia cerebral. A Atividade Assistida por animais consiste na visitação, recreação e distração por meio do contato dos animais com as pessoas. Desenvolve o inicio de um relacionamento, propõe entretenimento, oportunidades de motivação, a fim de melhorar a qualidade de vida. Sendo um programa que envolve o contato do animal com o ser humano é evidenciado o importante papel do médico veterinário, também como educador, orientando seus clientes a resolverem problemas pertinentes a manejo em relação ao comportamento dos animais, ensinando sobre cuidados necessários para o bem-estar animal da espécie inserida no programa de zooterapia, noções de higiene e saúde para prevenção de doenças. Foram divididos dois grupos onde o Grupo I participou da atividade assistida por animais e o Grupo II recebeu as orientações a respeito de higiene e saúde e assistência com uso da atividade assistida por animais. 
SANTOS, P.R. e SOUZA, F.S. O uso da atividade assistida por animais em pacientes com paralisia cerebral na cidade de Manaus-AM. PUBVET, Londrina, V. 5, N. 37, Ed. 184, Art. $1243,2011$.

Os participantes demonstraram expressões faciais de alegria, sentimentos, bem-estar, onde alguns participantes compartilharam sua historia de vida com a equipe, repetiam palavras decorrentes das informações, dois dos participantes demonstraram medo, mais curiosidade e fazendo perguntas a respeito aos cães.

Palavras-chave: animal, bem-estar, atividade, alternativa, terapia.

\title{
The use of animal-assisted activity in patients with cerebral palsy in Manaus-AM
}

\begin{abstract}
The present study it looked to show the Animal Assisted Activity in patients with neurological disturbs focused in Cerebral palsy. The Animal assisted Activity consists in visits, recreation, and distraction between humans with animals. It develops a begin of a relationship, it brings an entertainment, opportunity of motivation to have a better life quality. Since it's a program that it involves an animal, it's important the participation of a veterinarian on the project. The veterinarian will guide and show how to resolves problems with animal health care, animal behavior, and prevention diseases. Group I had information about heath care and zoonosis, and group II had informations about health care plus animal assisted activity. The participants showed facial expression of happiness, well bein, where some of them shared their life story with the project team. Two of them showed fear, but curiosity and making questions about the dogs.
\end{abstract}

Keywords: animal, well being,activity, alternative, therapy.

\section{INTRODUÇÃO}

Os animais, principalmente os de companhia, têm ocupado papel de destaque entre as famílias brasileiras, sendo considerados como rico auxílio, 
SANTOS, P.R. e SOUZA, F.S. O uso da atividade assistida por animais em pacientes com paralisia cerebral na cidade de Manaus-AM. PUBVET, Londrina, V. 5, N. 37, Ed. 184, Art. $1243,2011$.

por exemplo, no trabalho pedagógico com crianças. Daí a crescente inserção de ações envolvendo animais com diferentes finalidades, ora atuando para fins terápicos ora em atividades assistidas consistindo na visitação, recreação e distração por meio do contato dos animais com as pessoas, com intuito de promover o bem-estar, sendo as visitas semanais ou esporádicas, podendo ser com pessoas e animais diferentes.

A Atividade Assistida por animais (AAA) consiste na visitação, recreação e distração por meio do contato dos animais com as pessoas, e através dela, desenvolvem o início de um relacionamento, propõem entretenimento, oportunidades de motivação, a fim de melhorar a qualidade de vida (MEDEIROS, 2004). Segundo Machado (2008) a melhora no estado psicosocial em humanos pode ocorrer de algumas maneiras por meio de diminuição da depressão, desenvolvimento psicomotor e sensorial a partir do contato direto com os animais, além de melhora na socialização e da auto-estima.

Geralmente, fazem parte dos programas envolvendo animais, crianças em pleno desenvolvimento ou com necessidades especiais; jovens e adultos com distúrbios psicológicos e neurológicos e idosos institucionalizados ou não. Enfim, qualquer pessoa que se sinta bem na presença de animais pode participar.

Sendo um programa multidisciplinar, cabe também a participação do médico veterinário, sua participação é indispensável para o desenvolvimento do programa de zooterapia.

Sendo assim, este profissional desempenha papel essencial no sentido de acompanhar as manifestações comportamentais do animal junto a adestradores e etólogos, assim como, no sentido de zelar pela saúde animal, manter os animais em perfeito estado de saúde, com o objetivo de melhorar sua qualidade de vida. Além de cuidados básicos, como alimentação balanceada, cuidados necessários para o bem-estar animal, higiene, vacinações e vermifugações periódicas, mecanismos de controle de ectoparasitas (SANTOS, 2006; ANDERLINI, 2007). 
SANTOS, P.R. e SOUZA, F.S. O uso da atividade assistida por animais em pacientes com paralisia cerebral na cidade de Manaus-AM. PUBVET, Londrina, V. 5, N. 37, Ed. 184, Art. $1243,2011$.

Um determinado grupo de pacientes que pode ser beneficiado pela atividade assistida seria os que sofrem de paralisia cerebral (SCHWARTZMAN, 1993). Uma criança com paralisia cerebral pode levar muito mais tempo do que uma criança normal para entender e armazenar uma informação, principalmente, em casos em que não são realizadas intervenções nas épocas esperadas (FINNIE, 1980). A atividade assistida por animais pode ser aplicada em áreas relacionadas ao desenvolvimento psicomotor e sensorial, no tratamento de distúrbios físicos, mentais e emocionais, em programas destinados a melhorar a capacidade de socialização ou na recuperação da auto-estima (SAN JOAQUÍN, 2002).

Segundo Gonçalves (2007), a cinoterapia demonstrou ser promissora e potencializadora de forma importante para realização de atividades psicomotoras, que acontece de forma lúdica, favorecendo o movimento ativo.

Devido à relevância do tema e a oportunidade de se avaliar, mesmo que superficialmente e por curto espaço de tempo, buscou-se no presente estudo, trabalhar a Atividade Assistida por Animais com pacientes portadores de paralisia cerebral em um abrigo municipal avaliando a aceitação e resposta dos mesmos a esta atividade utilizando o cão na promoção de bem-estar aos pacientes institucionalizados.

\section{MATERIAL E MÉTODO}

\section{Classificação do Estudo}

Tratou-se de um trabalho, qualitativo, realizado na Instituição de apoio a crianças e adolescentes Abrigo Moacyr Alves (AMA) da rede privada, na cidade de Manaus, localizada na Rua 07, S/N - Alvorada I. O período de observação foi de primeiro de setembro a 31 de outubro de 2010. 
SANTOS, P.R. e SOUZA, F.S. O uso da atividade assistida por animais em pacientes com paralisia cerebral na cidade de Manaus-AM. PUBVET, Londrina, V. 5, N. 37, Ed. 184, Art. $1243,2011$.

Seleções dos Participantes

A seleção dos participantes obedeceu a critérios com base no grau da doença, histórico dos mesmos quanto a restrições de saúde à aproximação de animais, e posteriormente realizado um sorteio dentre estes moradores passíveis a participação no trabalho selecionando-se o número desejado.

A instituição abriga 54 moradores que apresentam paralisia cerebral, no qual 25 institucionalizados apresentam paralisia cerebral de grau leve, destes foram selecionados 14 participantes para compor os dois grupos (I e II), sendo o primeiro sorteado fazendo parte do grupo I, o segundo do grupo II e assim sucessivamente.

Os indivíduos foram identificados por meio de letras variando de " $\mathrm{A}$ " a "G" para os sete participantes do Grupo I e de "H" a "O " no Grupo II, de forma a preservar a identidade dos mesmos.

Coleta de Dados, Divisão de Grupos e Período de Observação

Para as observações os grupos selecionados foram categorizados em:

Grupo I - Pacientes observados quanto a inclusão da atividade assistida por animais.

Grupo II - Pacientes que receberam as orientações a respeito de higiene e saúde sem a presença de animais.

Foram realizadas, em média, três sessões por semana com uma hora de duração em cada um dos grupos formados no período envolvendo os dias 1 de setembro a 31 de outubro de 2010.

Seleção dos Cães

Foram utilizados um cão da raça Beagle e um canino Lulu da Pomerânia para a realização do presente trabalho. Como critérios para a seleção dos 
SANTOS, P.R. e SOUZA, F.S. O uso da atividade assistida por animais em pacientes com paralisia cerebral na cidade de Manaus-AM. PUBVET, Londrina, V. 5, N. 37, Ed. 184, Art. $1243,2011$.

animais foram avaliados questões sobre a necessidade de: adestramento, comportamento equilibrado, animais dóceis, treinamento constante, a vacinação em dia e ótimo estado de saúde.

Observação da Influência da Atividade Assistida por Animais

Uma avaliação prévia realizada pela terapeuta da instituição foi realizada com a finalidade de adequar as atividades ao uso dos cães e providenciar medidas que evitassem a exposição dos pacientes a riscos desnecessários, bem como expor o perfil de cada participante.

As observações foram conduzidas com o Grupo I três vezes por semana, onde o animal era conduzido até o local de realização das atividades juntamente a um adestrador. $\mathrm{O}$ animal era levado até o local e logo ao término das sessões, era recolhido pelos promotores das avaliações.

Foi avaliada a situação do paciente antes, durante e depois da abordagem com a atividade envolvendo o animal.

Durante a visita do animal, observou-se cada paciente, suas reações, comportamentos e atitudes, registrando-os por escrito em um diário de cada indivíduo.

Ao final da abordagem foram reunidas as observações anteriores e posteriores as sessões sendo os dados confrontados para obtenção de respostas aos objetivos propostos.

Observação da Resposta a Orientação sobre Cuidados de Higiene e Saúde

A abordagem foi feita por meio de vídeos pré-elaborados além de apresentações de imagens elaboradas para passar informações sobre o tema a um público de faixa etária até sete anos do Grupo II. 
SANTOS, P.R. e SOUZA, F.S. O uso da atividade assistida por animais em pacientes com paralisia cerebral na cidade de Manaus-AM. PUBVET, Londrina, V. 5, N. 37, Ed. 184, Art. $1243,2011$.

Aspectos Éticos da Pesquisa

Antes de iniciar a pesquisa, foi mostrado o pré-projeto da pesquisa para a diretoria do abrigo, visando do que se trata a Atividade Assistida por Animais e benefícios.

Após a autorização da instituição foi apresentado um termo de compromisso dos observadores do trabalho incluindo a não divulgação de imagens dos participantes sendo então iniciado o trabalho de avaliação dos institucionalizados selecionados.

\section{RESULTADOS E DISCUSSÃO}

Durante o período de realização do estudo compreendido entre primeiro de setembro e 31 de outubro de 2010, foram realizadas no total 19 sessões tanto para o Grupo I quanto para o Grupo II.

A equipe composta por um indivíduo sendo o observador, um adestrador profissional e uma terapeuta do local, juntamente com os animais foram os responsáveis pelas atividades após as 15:00h, três vezes na semana, para a desenvoltura da presente avaliação. O horário de início das atividades foi acordado desta forma, em função da rotina estabelecida aos institucionalizados, constituída da seguinte forma: pela manhã eles iam à escola, sendo grande parte dos pacientes freqüentadores da Associação dos Pais e Amigos dos Excepcionais (A.P.A.E.) ou iam até a Sociedade Pestalozzi e outros ainda frequentavam escolas de ensino fundamental pública ou privada.

Até as 15:00h os moradores do abrigo tinham atividades e terapias com fisioterapeutas, odontólogos, psicólogo e assistente social. Somente após as 15:00h é que os indivíduos teriam tempo livre para outras atividades como assistir televisão, ouvir música, dançar etc.

As sessões de uma hora de duração eram realizadas após a rotina de atividades elaborada pela instituição aos indivíduos institucionalizados, tendo 
SANTOS, P.R. e SOUZA, F.S. O uso da atividade assistida por animais em pacientes com paralisia cerebral na cidade de Manaus-AM. PUBVET, Londrina, V. 5, N. 37, Ed. 184, Art. $1243,2011$.

início às 16:00h com duração até as 17:00h para o Grupo I (Atividade assistida com animais) e na sequência iniciando às 17:00h e terminando as 18:00h com o Grupo II (Atividades de educação em saúde sem a presença dos animais). Este procedimento fora adotado para que não houvesse prejuízo nas atividades regulares dos pacientes e não interferisse na rotina da instituição.

A seguir foram expostas as informações fornecidas pela psicóloga responsável pela instituição, sobre o perfil apresentado por cada um dos componentes de ambos os grupos antes do início dos trabalhos de observação com o uso dos cães e da exposição de temas sobre cuidados pessoais/higiene sem animais. Concomitantemente, foi demonstrada a resposta, seja positiva ou negativa, de cada participante de ambos os grupos, após as atividades propostas segundo a avaliação do observador.

Resultados Relativos ao Grupo I

As atividades realizadas com os participantes desde grupo incluíam sempre os cães como um instrumento de ensino-aprendizagem para novos conhecimentos e diferentes diálogos. Foram também demonstrados truques que os cães sabiam fazer. Com a introdução dos animais, os pacientes espontaneamente fizeram perguntas relacionadas ao próprio animal.

Indivíduo "A" - Idade: 19 anos. Histórico: "A" apresenta distúrbio mental. Ficava trancado em casa assistindo TV e deixou de freqüentar a escola onde estudava por não ter quem o levasse. O tio trabalhava no distrito industrial. "A" ficava de segunda a sexta feira na instituição, no sábado ia para casa e retornava no domingo para o abrigo.

" $A$ " mostrou-se receptivo com a equipe, mostrando interesse em relação aos animais, porém teve medo de interagir com o cão. Na terceira sessão " $A$ " 
SANTOS, P.R. e SOUZA, F.S. O uso da atividade assistida por animais em pacientes com paralisia cerebral na cidade de Manaus-AM. PUBVET, Londrina, V. 5, N. 37, Ed. 184, Art. $1243,2011$.

começou a interagir com o animal, tocando o pêlo do mesmo, fazendo perguntas e chamando o cão pelo nome.

O indivíduo "B" - Idade: 23 anos. Histórico: "B" apresenta deficiência mental leve, sofreu violência sexual e não recebia visita dos familiares.

"B" mostrou-se também receptivo com a equipe. Demonstrando curiosidade a respeito dos cães, pedindo pra levá-los sempre ao abrigo quando houvesse o retorno da equipe, mas quando o animal estava presente, " $B$ " demonstrava medo. A partir da quinta sessão começou a interagir diretamente com o animal, sendo que, só demonstrava interesse quando se conduzia o animal até ela.

Indivíduo "C" - Idade: 19 anos. Histórico: Não recebia visita de familiares, somente de pais de consideração. Apresentava crises convulsivas, frequentava escola especial, possuindo deficiência mental e epilepsia.

" $C$ " apesar de ser agressivo e apresentar rebeldia, desde a primeira sessão interagiu com a equipe e com o cão, querendo conduzir sempre o animal pelo abrigo.

Indivíduo "D" - Idade: 24 anos. Histórico: "D" era portador de deficiência mental leve e estudava na Sociedade Pestalozzi.

" $D$ " foi receptivo com a equipe, mostrando interesse pelos cães, ficando perto dos mesmos, mas em nenhum momento houve interação com os animais.

Indivíduo "E" - Idade: 24 anos. Histórico: "E" apresentava deficiência física e mental. Foi abandonada na Antiga Intendência de Menores por uma senhora não identificada. Encontrava-se bem adaptada ao abrigo e estudava em escola especial.

"E" desde a primeira sessão interagiu com a equipe e com os animais, mostrando alegria e sorrisos. 
SANTOS, P.R. e SOUZA, F.S. O uso da atividade assistida por animais em pacientes com paralisia cerebral na cidade de Manaus-AM. PUBVET, Londrina, V. 5, N. 37, Ed. 184, Art. $1243,2011$.

Indivíduo "F" - Idade: 16 anos. Histórico: "F" vivia na rua, foi maltratado e apresentava comprometimento mental. " $F$ " ficou muito tempo na rua. Recentemente morava no abrigo e estudava na Pestalozzi. " $F$ " desde o inicio foi bastante receptivo com a equipe e com os animais, interativo. Sempre deslizava as mãos sobre o pêlo do cão e chamava o animal pelo nome.

Indivíduo "G" - Idade: 29 anos. Histórico: "G" foi abandonada pelos familiares e tinha deficiência mental, apresentando também um retardo do desenvolvimento psíquico. Esteve grávida, mas a criança ao nascer foi retirada da mesma pelos familiares.

"G" sempre foi receptiva e interagia com a equipe, porém não interagia com os cães, só os observava, mas, na décima sétima sessão, aproximou-se do cão, alimentou-o com petiscos, sorrindo e tocando o pêlo do animal.

Os resultados do grupo I foram pouco promissores, este fato deve-se talvez ao reduzido período de contatos dos pacientes com este tipo de atividade. Porém Dotti (2005) descreve que há comprovações de que períodos de quinze a vinte minutos de atividade com os animais já seriam suficientes para uma harmonização fisiológica com regulamentação da pressão arterial, do batimento cardíaco e de reações químicas benéficas em diferentes sentidos. Aqueles indivíduos que demonstraram atitudes positivas de aceitação e de melhora no relacionamento com a equipe e com os animais estão em concordância com as observações de Becker (2003) quando este cita a melhora psicológica de uma pessoa quando afaga um animal. Ato este que promove a liberação de substâncias pelo corpo do indivíduo que reforçam o sistema imunológico e refletem no estado emocional ainda podendo estimular a aprendizagem, memória, coordenação motora, o alivio de sensações de estresse, ansiedade ou dor. 
SANTOS, P.R. e SOUZA, F.S. O uso da atividade assistida por animais em pacientes com paralisia cerebral na cidade de Manaus-AM. PUBVET, Londrina, V. 5, N. 37, Ed. 184, Art. $1243,2011$.

De qualquer forma, houve um benefício direto ou indireto a estes pacientes, pois segundo alguns pesquisadores e psicólogos, como descritos por Silva (2009), afirmam que as interações estimuladas pela presença do cão mesmo por um contato social casual, proporcionam maior bem psicológico aos indivíduos. Isto pode ser reforçado de modo prático por meio do relato de Crawford (2003) que resolveu levar uma cadela no local do acidente das torres gêmeas do World Trade Center para trazer um pouco de conforto para os familiares das vitimas e aos bombeiros que estavam fazendo as buscas, percebendo na ocasião que na presença do cão foi feito com que os familiares das vitimas lembrassem alguma forma seus entes que estavam no acidente e assim trazendo conforto.

Portando atividades que envolvam animais podem gerar efeitos benéficos aos indivíduos em contato com eles permitindo a melhora no tratamento de distúrbios físicos, mentais e emocionais, em programas destinados a melhorar a capacidade de socialização ou na recuperação da auto-estima e podem ser direcionados a pessoas de diferentes faixas etárias, instituições penais, hospitais, casas de saúde, escolas e clínicas de recuperação, ressaltando novamente, a potencialização de resultados (SAN JOAQUÍN, 2002; GONÇALVES, 2007).

Resultados Relativos ao Grupo II

Indivíduo "H" - Idade: 15 anos. Histórico: "H" tinha micro cefaléia e retardamento leve. Sofreu maus tratos e desnutrição. Os pais não tinham condições de ter a guarda da criança.

Indivíduo "I" - Idade: 26 anos. Histórico: "I" deficiente físico e mental, foi vitima de maus tratos e abandono por parte de seus familiares. O padrasto era alcoólatra e a mãe mudou-se para outro estado com o resto da família. Apresentava hematomas e machucados pelo corpo. 
SANTOS, P.R. e SOUZA, F.S. O uso da atividade assistida por animais em pacientes com paralisia cerebral na cidade de Manaus-AM. PUBVET, Londrina, V. 5, N. 37, Ed. 184, Art. $1243,2011$.

Indivíduo "J" - Idade: 16 anos. Histórico: "J". Apresentava deficiência mental. Foi abandonado em frente a uma rede de televisão local junto com uma pasta contendo alguns documentos de identificação. Encontrava-se abrigado na instituição a aproximadamente cinco anos.

Indivíduo "L" - Idade: 16 anos. Histórico: "L" encontrava-se institucionalizada desde os oito anos de idade, em razão do abandono por parte da família de paradeiro totalmente desconhecido. Era deficiente mental, estudava na Sociedade Pestalozzi. Era participativo, procura ajudar nas atividades da casa e gostava de participar das atividades pedagógicas e lúdicas.

Indivíduo "M" - Idade: 16 anos. Histórico: "M" apresentava distúrbios neurológicos e alergia a dipirona. Tinha dificuldade de mastigar, dormia sempre com alguém ao lado. " $\mathrm{M}$ " encontrava-se no abrigo, porém recebia visitas.

Indivíduo "N" - Idade: 9 anos. Histórico: "N" apresentava paralisia cerebral leve, foi encaminhado ao abrigo, porque os vizinhos falavam que a criança ficava sozinha em casa. Foi abandonado por sua mãe biológica e há meses ninguém sabia de seu paradeiro.

Indivíduo "O" - Idade: 16 anos. Histórico: "O" apresenta paralisia cerebral leve. Não freqüenta a escola por causa da depressão.

Os participantes deste grupo conseguiram absorver parte das informações transmitidas sobre higiene e zoonoses. Apresentaram melhor aprendizado por meio de imagens impressas. Pois quando do início do trabalho eram apresentados vídeos, os participantes ficavam dispersos, ou seja, não 
SANTOS, P.R. e SOUZA, F.S. O uso da atividade assistida por animais em pacientes com paralisia cerebral na cidade de Manaus-AM. PUBVET, Londrina, V. 5, N. 37, Ed. 184, Art. $1243,2011$.

demonstrando interesse pelo material, resultando até em desentendimento entre eles.

Contudo, observa-se que mesmo indivíduos portadores de paralisia cerebral foram capazes de reter alguns itens relacionados a um nível de informação diferenciado demonstrando na forma de repetições de palavras soltas e por meio de perguntas. Portanto, os distúrbios não inviabilizavam, aparentemente, determinadas atividades, pois é tido como uma das rotinas dos indivíduos institucionalizados a frequência pelo turno da manhã em algum tipo de escola. O que pode ocorrer nestes casos é que haja uma demora no aprendizado comparado a um indivíduo normal como colocado por Finnie (1980).

Estes indivíduos não tiveram contato com os animais, diferentemente dos integrantes do Grupo I, apresentando os mesmos sintomas e comportamentos decorrentes da problemática motivada pela paralisia cerebral ao contrário dos indivíduos do Grupo I que pelo relacionamento passageiro com os animais demonstraram reações diferenciadas para melhor no sentido de atitudes e relacionamentos.

\section{CONCLUSÕES}

Em função dos objetivos propostos pôde-se concluir que houve uma aceitação por parte de alguns integrantes do Grupo I as atividades assistidas com animais com consequente promoção de bem-estar no grupo destes pacientes e a realização de algumas orientações básicas sobre higiene e saúde aos pacientes selecionados do Grupo II, com relativo sucesso sem a utilização de cães mantendo-se comportamento e atitudes iguais ao início das observações. 
SANTOS, P.R. e SOUZA, F.S. O uso da atividade assistida por animais em pacientes com paralisia cerebral na cidade de Manaus-AM. PUBVET, Londrina, V. 5, N. 37, Ed. 184, Art. 1243, 2011.

\section{AGRADECIMENTOS}

Ao adestrador Fabio Gato Lopes pelo apoio na realização do trabalho e aos dirigentes do Abrigo Moacyr Alves pela autorização para a realização do mesmo.

\section{REFERÊNCIAS BIBLIOGRÁFICAS}

ANDERLINI, G. Benefícios do envolvimento do animal de companhia (cão e gato) na terapia, socialização e bem estar das pessoas e o papel do medico veterinário. Revista do Conselho de Medicina veterinária, n. 31, p. 70, 2007.

BECKER, M. The healing power of pets. Rio de Janeiro: Ed. Bertrand Brasil. 2003.

CRAWFORD, J. Therapy pets; the animal-human healing partnership. 2003.

DOTTI, J. Terapia e Animais. São Paulo: Editora PC Editoria. 2005.

FINNIE, N. A. O manuseio em casa da criança com paralisia cerebral. Tradução: Júlio Pinto Duarte. São Paulo: Editora Manole Ltda. 1980.

GONÇALVES, H. J. Estimulação psicomotora de crianças com encefalopatia não progressiva da infância através da cinoterapia.2007. Disponível em: http//; http://www.animaisterapeutas.com.br/docs/estimula\%E7\%E3o_psicomotora_atrav\%E9s_da_c inoterapia.pdf. Acesso em: 25/09/2010.

MACHADO, J. Terapia assistida por animais. Revista cientifica veterinária. Ano VI, n. 10, 2008.

MEDEIROS, A. J. Terapia Assistida por Animais a crianças hospitalizadas 2004: Revisão bibliográfica. Disponível em: http://www.prp.unicamp.br/pibic/congressos/xvicongresso/paineis/058832.pdf Acesso em: $10 / 10 / 2010$.

SAN JOAQUÍN, M. P. Z. Terapia asistida por animales de conpañia. Bienestar para el ser humano. Temas de Hoy, p.143-149, 2002.

SANTOS, K. Terapia assistida por animais; uma experiência além da ciência/Karen Cristini dos Santos. São Paulo: Editora Paulinas, 2006-coleção Vida assistida.

SCHWARTZMAN, J. S. Paralisia cerebral. Temas Sobre Desenvolvimento, v. 3, n. 13, p. 4-21, 1993.

SILVA, M. R. Bem-estar animal em programas de zooterapia ou terapia assistida por animais. PUBVET, Londrina,v. 3, n. 20, Ed. 81, Art. 57, ISSN 1982-1263, 2009. Disponível em: http://www. pubvet.com.br/busca.asp?busca=Bemestar+animal+em+programas+de+zooterap $\mathrm{ia}+\mathrm{ou}+$ terapia+assistida+por+animais\&campo $=$ titulo\&categoria $=1 \& \mathrm{x}=12 \& \mathrm{y}=6$. Acesso em $10 / 10 / 2010$. 